\title{
POSITRON LIFETIME MEASUREMENTS IN NATURAL RUBBER WITH DIFFERENT FILLERS
}

\author{
A. MANDAL \\ Physics Department, Visva-Bharati Central University, P.O.- Santiniketan, West Bengal, \\ India, Pin-731235, arunava2007@gmail.com \\ S. MUKHERJEE \\ Physics Department, Visva-Bharati Central University, P.O.- Santiniketan, West Bengal, \\ India, Pin731235, teacher.subrata@gmail.com \\ S. PAN \\ Physics Department, Visva-Bharati Central University, P.O.- Santiniketan, West Bengal, \\ India, PIN-731235, pansandip79@gmail.com \\ A. SENGUPTA* \\ Physics Department, Visva-Bharati Central University, P.O.- Santiniketan, West Bengal, \\ India, PIN-731235 \\ *Corresponding Author, asmita_sengupta@hotmail.com
}

\begin{abstract}
Positron annihilation lifetime spectra (PLAS) have been measured for natural rubber polymer with different fillers (Titenium dioxide, Nanosilica and Nanoclay) as a function of filler concentration to investigate how these fillers affect the microstructure of free volume of natural rubber. The lifetime spectra is analyzed by using LT9.0 and the longest lived component $\left(\tau_{\mathrm{o}-\mathrm{Ps}}\right)$ is attributed to the pick- off annihilation of o-Ps in free volume sites, available mostly in the amorphous region of polymer. On the basis of the $\tau_{\mathrm{o}-\mathrm{Ps}}$ values the radii of the free volume holes $\left(\mathrm{R}_{\mathrm{h}}\right)$ are calculated. The PALS results show that o-Ps lifetime as well as the size of free volume decreases with the increase of filler concentration.
\end{abstract}

Keywords: Positron annihilation lifetime, Natural rubber, Different fillers.

\section{Introduction}

Raw natural rubber (NR) undergoes curing process for it to be useful for any practical and industrial purpose. It is therefore compounded by mixing with varity of materials such as sulfur, zinc oxide, stearic acid etc. and then cure in a process called vulcanization. ${ }^{1}$ During this process, NR forms cross links with sulfur improving its quality and usefulness. ${ }^{2-4}$ The free volume concepts play an important role in polymer research and widely used to describe and explain the behavior of physical properties such as glass transition temperature, viscosity, stiffness and strength. Free volume is affected by aging and by addition of various fillers. ${ }^{5}$ A key problem is to relate the macroscopic mechanical properties of polymer to atomic scale free volume holes. Therefore the 
investigation of microstructure and the conductive mechanism of polymers is still of great significance in material science and in industry.

Positron annihilation lifetime spectroscopy (PALS) has been widely applied to microstructure determination in polymer giving direct information on free volume size and concentration. ${ }^{6-8}$ It is an ideal non destructive method for the detail microstructure study of polymer and polymer with fillers ${ }^{6}$ and it has two prominent advantages, firstly the ability to detecting down to the atomic scale and secondly the high sensitivity to the microstructure change of $1 \mathrm{ppm}$. An energetic Positron $\left(\mathrm{e}^{+}\right)$enters a polymeric material, from a radioactive source, slows down to thermal energy and finally captures an electron to form a bound state called positronium (Ps). ${ }^{9}$ The positronium is known to exist in two states, para-positronium (p-Ps) and ortho-positronium (o-Ps) with a relative abundance of $1: 3 .^{10}$ Confined within a free volume in polymer, the long lived o-Ps has a finite probability of annihilating with an electron other than its bound partner (and of opposite spin), following a process called "pick-off" annihilation. ${ }^{11,6}$ The changes in o-Ps lifetime and intensity can be related to the size of the hole that confines the o-Ps. ${ }^{12}$ In this paper a detail investigation of the effect on microstructure of free volume as well as the physical properties due to the addition of different fillers of different concentrations in natural rubber has been made by PALS.

\section{Experimental}

\subsection{Samples}

Natural Rubber (NR) used for the study is procured from the Rubber Research Institute of India, Kottayam. All ingredients used for formulation of composite mixes are of commercial grade and are kindly supplied by LANXESS. NR samples are filled with $\mathrm{TiO}_{2}$ (10phr, 20phr, 30phr, 40phr), Nanosilica (5phr,10phr,20phr) and Nanoclay (2 phr, $5 \mathrm{phr}, 10 \mathrm{phr})$ for the measurements. The filler titanium dioxide, $\mathrm{TiO}_{2}(\mathrm{KEMOX} \mathrm{RC}$ 800 PG), is kindly supplied by Kerala Minerals and Metals Limited (KMML) Kollam, India. The surface modified Nanosilica (AEROSIL R 8200) is obtained from Degussa, Germany.

\subsection{Measurements of the samples}

\subsubsection{Positron annihilation lifetime spectroscopy}

Positron annihilation lifetime spectroscopy (PALS) experiment is carried out at room temperature $\left(25^{\circ} \mathrm{C}\right)$ using a fast-fast coincident system. ${ }^{13,14}{ }^{22} \mathrm{Na}$ positron source of activity $20 \mu \mathrm{Ci}$ is sandwiched between two identical pieces of samples of thickness $1.5 \mathrm{~mm}$, wrapped by well annealed Al foils. The source sample sandwich is placed between two $\mathrm{BaF}_{2}$ scintillation detectors mounted on two photomultiplier tubes. The time resolution of the lifetime system has been 320 ps. Each lifetime spectrum is analyzed with two components by using the standard LT9.0 computer program with proper source and background correction. 


\section{Results and discussion}

\subsection{Analysis of lifetime spectra}

The short lived lifetime component $\left(\tau_{\mathrm{p}-\mathrm{Ps}}\right)$ is attributed to the annihilation of p-Ps and the long lived component $\left(\tau_{\mathrm{o}-\mathrm{Ps}}\right)$ is attributed to the pick-off annihilation of o-Ps in free volume sites, available mostly in the amorphous region of polymer.

Assuming the shape of the free volume holes (sphere, cylinder, cube), the hole volume can be related to the lifetime of pick-off reaction of o-Ps $\left(\tau_{0-\mathrm{Ps}}\right)$, using a semiempirical model, Tao-Eldrup model. ${ }^{16,11}$ The $\left(\tau_{\mathrm{o}-\mathrm{Ps}}\right)$ is given by

$$
\tau_{o-p s}=0.5 n s\left[1-\frac{R_{h}}{R_{h}+\partial R}+\frac{1}{2 \pi} \operatorname{Sin}\left(\frac{2 \pi R_{h}}{R_{h}+\partial R}\right)\right]^{-1}
$$

Where $\partial \mathrm{R}=1.66 \AA$, the penetration depth of the Ps wave function into the hole wall and the pre factor $0.5 \mathrm{~ns}$ is the spin average of the Ps -annihilation lifetime. ${ }^{15-17}$ The mean volume of the hole $\left(\mathrm{V}_{\mathrm{h}}\right)$ and the free volume fraction $\left(\mathrm{V}_{\mathrm{f}}\right)$ can be calculated from

$$
V_{h}=\frac{4}{3} \pi R_{h}^{3}
$$

$$
V_{f}=A V_{h} I_{o-p s}
$$

Where $A$ is a constant, $V_{h}$ is the mean free volume and $V_{f}$ is the free volume fraction. ${ }^{18}$ The free volume and relative free volume fraction are calculated using above relations. The results are presented in the following figures.

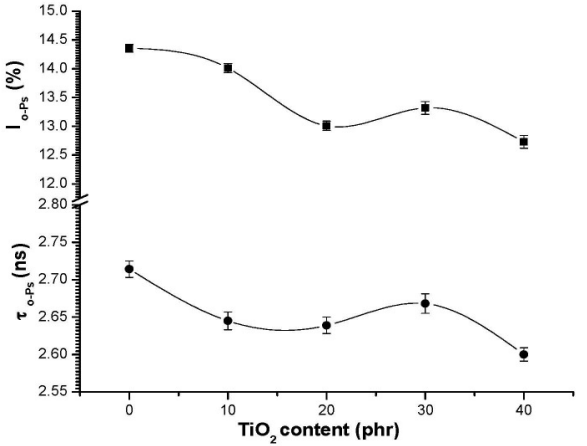

(a)

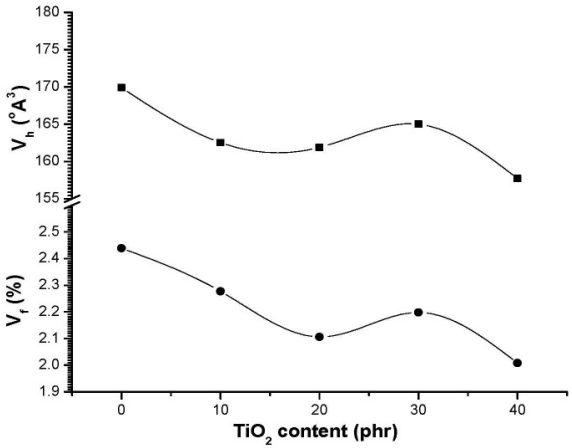

(b)

Fig.1. (a) Variation of o-Positronium lifetime $\left(\tau_{\mathrm{o}-\mathrm{Ps}}\right)$ and Intensity $\left(\mathrm{I}_{\mathrm{o}-\mathrm{Ps}}\right)$ with $\mathrm{TiO}_{2}$ concentrations (b) variation of free volume size $\left(\mathrm{V}_{\mathrm{h}}\right)$ and free volume fraction $\left(\mathrm{V}_{\mathrm{f}}\right)$ with $\mathrm{TiO}_{2}$ concentrations

Fig.1(a). shows the variation of o-Ps lifetime $\left(\tau_{\mathrm{o}-\mathrm{Ps}}\right)$ and intensity $\left(\mathrm{I}_{\mathrm{o}-\mathrm{Ps}}\right)$ with the addition of $\mathrm{TiO}_{2}$ filler having different concentrations. As we increase the filler concentration up to $20 \mathrm{phr}$ both the lifetime and intensity decreases. In the region 20 to $30 \mathrm{phr}$ a small increase in both the lifetime and intensity is observed which do not exceed the value for 
the reference sample and finally decrease to the lowest value at $40 \mathrm{phr}$. The decrease in $\tau_{\mathrm{o}-\mathrm{Ps}}$ and $\mathrm{I}_{\mathrm{o}-\mathrm{Ps}}$ with increasing $\mathrm{TiO}_{2}$ concentration indicates that the addition of $\mathrm{TiO}_{2}$ inhibits the o-Ps formation. This can be explained in two ways. Firstly the $\mathrm{TiO}_{2}$ particles fill up some of the free volume holes in NR and decrease the size and concentration of free volume in NR and thus the life time and intensity of o-Ps decrease. Secondly positrons may annihilate from $\mathrm{TiO}_{2}$ filler and there is a lack of positrons available to form positronium in NR. ${ }^{15}$ The increase of $\tau_{\mathrm{o}-\mathrm{Ps}}$ and $\mathrm{I}_{\mathrm{o}-\mathrm{Ps}}$ with $\mathrm{TiO}_{2}$ concentration (20-30 phr) is indicating that the addition of filler creates new positron trapping sites at the $\mathrm{TiO}_{2}-\mathrm{NR}$ interface. Fig. 1(b). shows the variation of free volume hole size $\left(\mathrm{V}_{\mathrm{h}}\right)$ and free volume fraction $\left(\mathrm{V}_{\mathrm{f}} \%\right)$ with $\mathrm{TiO}_{2}$ concentration. As filler concentration increase, the filler particles are distributed in-between the molecular chains of NR and reduce the size of free volumes within the samples which causes decrease in the o-Ps lifetime in NR and results in a linear regression in the free volume size. Fig. 2(a). shows the variation of $\tau_{0-\mathrm{Ps}}$ and $\mathrm{I}_{\mathrm{o}-\mathrm{Ps}}$ with NS filler concentrations. From the figure it is found that as the filler concentration increase from 5 to $10 \mathrm{phr}$ the rate of o-Ps formation in NR reduces and causes a decrease in both $\tau_{\mathrm{o}-\mathrm{Ps}}$ and $\mathrm{I}_{\mathrm{o}-\mathrm{Ps}}$. As earlier, the two logical reasons are, firstly the

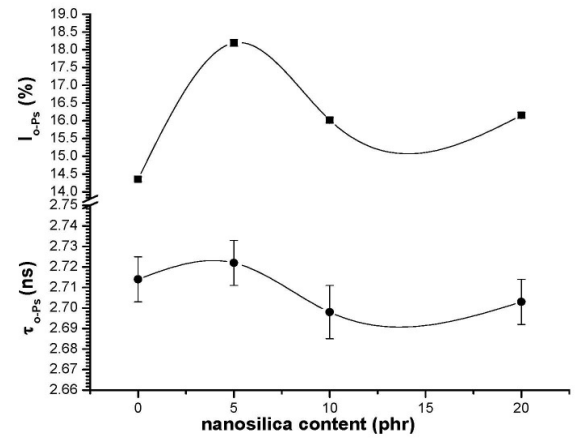

(a)

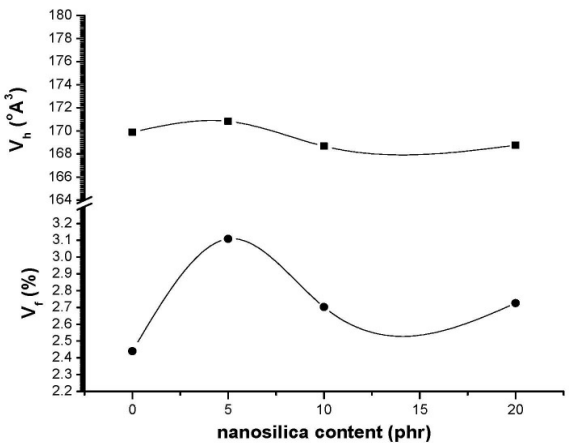

(b)

Fig.2. (a) Variation of o-Positronium lifetime $\left(\tau_{\mathrm{o}-\mathrm{Ps}}\right)$ and Intensity $\left(\mathrm{I}_{\mathrm{o}-\mathrm{Ps}}\right)$ with nanosilica concentrations

(b) variation of free volume size $\left(\mathrm{V}_{\mathrm{h}}\right)$ and free volume fraction $\left(\mathrm{V}_{\mathrm{f}}\right)$ with nanosilica concentrations

NS particles fill up some of the free volume holes in NR and decrease the size and concentration of free volume holes in NR. Secondly, there is a lack of positrons available to form o-Ps in NR due to the annihilation of positron from the filler (NS) added. But both $\tau_{\mathrm{o}-\mathrm{Ps}}$ and $\mathrm{I}_{\mathrm{o}-\mathrm{Ps}}$ begin to increase as the filler concentration rises from 10 to $20 \mathrm{phr}$. This increase indicates the creation of some new positron trapping sites at interface. Fig. 2(b). shows the variation of free volume hole size $\left(\mathrm{V}_{\mathrm{h}}\right)$ and free volume fraction $\left(\mathrm{V}_{\mathrm{f}} \%\right)$ with nanosilica concentrations. The variations also support the above interpretation. In Fig. 3(a). the variation of $\tau_{\mathrm{o}-\mathrm{Ps}}$ and intensity $\mathrm{I}_{\mathrm{o}-\mathrm{Ps}}$ with $\mathrm{NC}$ concentrations are shown. It is found that the increase of NC concentration reduces the o-Ps formation in NC-NR interface and causes a decrease in both $\tau_{\mathrm{o}-\mathrm{Ps}}$ and $\mathrm{I}_{\mathrm{o}-\mathrm{Ps}}$ upto a concentration of $2 \mathrm{phr}$. The 
figure shows a gradual decrease in $\tau_{\mathrm{o}-\mathrm{Ps}}$ as well as an increase in $\mathrm{I}_{\mathrm{o}-\mathrm{ps}}$ beyond $2 \mathrm{phr}$. Fig. 3(b). shows the variation of free volume hole size $\left(\mathrm{V}_{\mathrm{h}}\right)$ and free volume fraction $\left(\mathrm{V}_{\mathrm{f}} \%\right)$ with $\mathrm{NC}$ concentrations. With increase of filler concentration there is a linear regression in the free volume size within the sample which signifies the decrease in $\tau_{\mathrm{o}-\mathrm{Ps}}$. As the free volume fraction $\left(\mathrm{V}_{\mathrm{f}} \%\right)$ is directly related to $\mathrm{I}_{\mathrm{o}-\mathrm{Ps}}$ (Eq.3.) the increase of it indicates the increase of number of $\tau_{\mathrm{o}-\mathrm{Ps}}$ trapping sites, not the size of the free volumes $\left(\mathrm{V}_{\mathrm{h}}\right)$ which might be due to the creation of some new positron trapping sites at NC-NR interface. Thus, these fillers might act as active fillers for natural rubber and increase its strength and stiffness.

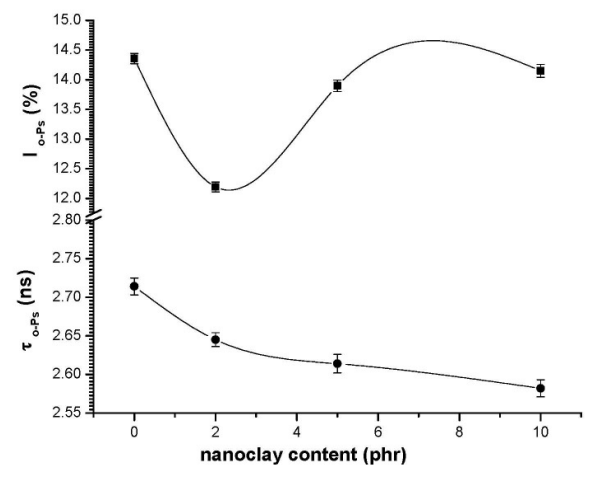

(a)

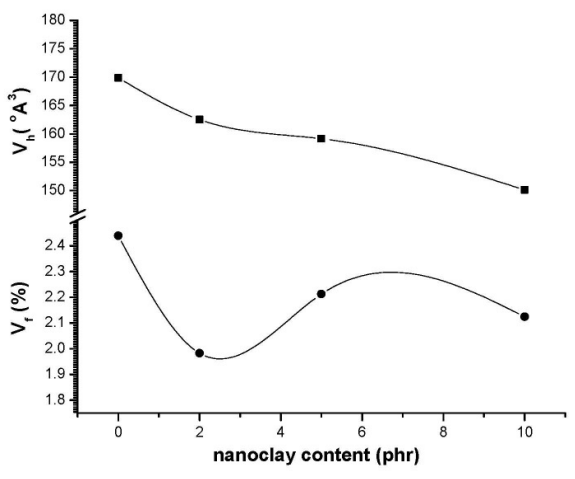

(b)

Fig.3. (a) Variation of o-Positronium lifetime $\left(\tau_{0-\mathrm{Ps}}\right)$ and Intensity $\left(\mathrm{I}_{\mathrm{o}-\mathrm{Ps}}\right)$ with nanoclay concentrations (b) variation of free volume $\operatorname{size}\left(\mathrm{V}_{\mathrm{h}}\right)$ and free volume fraction $\left(\mathrm{V}_{\mathrm{f}}\right)$ with nanoclay concentrations

\section{Conclusion}

Positron lifetime data of natural rubber filled with three different fillers $\left(\mathrm{TiO}_{2}, \mathrm{NS}, \mathrm{NC}\right)$ of different concentrations have been analyzed .Distinct changes in positron parameters with respect to filler concentration have been observed from the experimental results. The change in the positron lifetime parameter with filler concentration reflects that the size and concentration of free volume holes decrease with the increase of filler concentration. Also the formation of new positronium trapping sites at the filler - NR interfaces have been evidenced. It may be concluded that these fillers act as active filler for natural rubber and hence can be used to improve the quality of the sample in terms of strength and stiffness.

\section{Acknowledgment}

The authors wish to acknowledge Prof. S. Thomas, M.G. University,Kerala, for providing the samples. The work is sponsored by SERC Division, D.S.T., Govt. of India, project No. SR/S2/CMP-57/2007, DAE,BRNS Project No. 2007/37/5/BRNS/234 and UGC Project No. F.No. 10-34/2008(SR). 


\section{References}

1. P. Munk and T. M. Aminabhavi (eds.). Introduction to Macromolecular Science. $2^{\text {nd }}$ ed. (John Wiley \& Sons. New York. 2002)

2. H. D. Heinze, K. Schmieder, G. Schnell and K. A. Wolf, Kaupsch. Gummi Kunstst. 14, 208 (1961)

3. O. Krames, S. Hvidt and J. D. Ferry, In Science and Technology of Rubber, Edited by J. E. Mark, B. Erman, and F. R. Eirich (Academic Press, San diego, 1994), p. 228

4. M. Mori and J. L. Koenig, Rubber Chem. Technol. 68, 551 (1995)

5. J. Wang, J. Vincent and C. A. Quarles, Nuclear Instruments and Methods in Physics Research B 241, 271-275(2005)

6. Y C. Jean, Microchem J. in Positron Annihilation, Proc. Of the $10^{\text {th }}$ Int. Conf. 42, 72( 1990)

7. O E. Mogensen, Positron Annihilation in Chemistry. (Springer-Verlag, Barlin 1995), p. 563.

8. Y. C. Jean, P. E. Mallon and D. M. Schrader. Eds. Principles and Application of Positron and Positronium Chemistry.( World Scientific, Singapore, 2003)

9. P. Hautojarvi, Positrons in solids. (Berlin, Singapore, 1989)

10. G. Dlubek, M. Q. Shaikh, R. Krause-Rehberg and M. Paluch, The Journal of Chemical Physics 126,0249006.( 2007)

11. S. J. Tao, J.Chem. Phy. 56, 5499 ( 1972)

12. R. A. Pethrick, Prog. Polym. Sci. 22, 1 (1997)

13. J. M. Urban-Klaehn and C. A. Quarles, J. Appl. Phys. 86, 355 (1999)

14. G. Dlubek, J. Pointeck, M. Q. Shaikh, E. M. Hassan and R. Krause-Rehberg, Physical Rev. E 75, 021802 (2007)

15. A. J. Marzocca, S. Cerveny, W. Salgueiro, A. Somoza and L. Gonzalez. Physical Rev. E 65, 021801-1-021801-5 (2002)

16. M. Eldrup, D. Lightbody and J. N. Sherwood, Chem. Phys. 63, 51(1981)

17. C. Wastlund and F. H. J. Maurer, Macromolecules 30, 5870 (1997)

18. E. E. Abdel-Hady, H. M. Abdel-Hadmid and F. M. Mohemed Hamdy, Radiation measurements 38, 211(2004) 